\title{
Peroxisome Biogenesis Disorder 3B
}

National Cancer Institute

\section{Source}

National Cancer Institute. Peroxisome Biogenesis Disorder 3B. NCI Thesaurus. Code C155753.

An autosomal recessive condition caused by mutation(s) in the PEX12 gene, encoding peroxisome assembly protein 12 . Peroxisome biogenesis disorder 3B is characterized by overlapping phenotypes of neonatal adrenoleukodystrophy and infantile Refsum disease. 